\title{
The meaning of the -er suffix
}

\author{
JOSEPH J. DALEZMAN \\ New College of the University of South Florida, Sarasota, Florida 33580
}

and

\author{
RUTH E. KNIGHT \\ University of Missouri, Columbia, Missouri 65201
}

\begin{abstract}
Through the use of the PI release methodology, the study empirically tested a basic linguistic introspective assumption that the -er suffix is semantically processed as two independent morphemes. The linguistic hypothesis was validated, since shifting from comparative adjectives to agentive nouns, all ending with an -er suffix, or vice versa, resulted in significant PI release. Later, final free recall indicated that the release from PI was a long-term memory phenomenon.
\end{abstract}

Over the past several decades, an organizational hierarchical analysis of language has been undertaken by linguists (Chomsky, 1956, 1965, 1966). As a result, a linguistic description of speech output can be broken down into basic hierarchical units: Phonemes form morphemes, morphemes form words, words form phrases, phrases form sentences, and, finally, sentences form language.

Morphemes are defined as the minimal phonemic units that possess meaning. A morpheme may be either a word or a part of a word. Stem morphemes are sequences of phonemes that are realized as full words (e.g., nouns, verbs, adjectives, etc.). Affixes are either prefixes or suffixes that are added to stem words to convey new meanings. Jarvella and Snodgrass (1974) and Murrell and Morton (1974) have provided empirical support for a morphemic analysis of stem words. However, as yet, no empirical data have been offered to support the morphemic validity of affixes. This is the major purpose of this study.

The experiment dealt specifically with words formed by adding an -er suffix to the stems. For example, the words "smaller" and "worker" are assumed to be composed of two independent morphemes: the base words "small" or "work" plus the suffix -er. In linguistic terminology, the addition of an -er suffix to an adjective forms the comparative degree, while the addition of an -er suffix to a verb signifies a doer of action and is called an agentive. Therefore, not only is it possible to decompose multisyllabic words into separate morphemes, but phonetically identical morphemes, such as the -er suffix, can also be processed as two distinct semantic categories.

This research is based in part on a paper presented at the Midwestern Psychological Association convention in Chicago, 1973. Requests for reprints should be sent to Joseph J. Dalezman, New College of the University of South Florida, Sarasota, Florida 33580.
Previous research has shown that when, over trials, the taxonomic class of word triads is shifted or changed, a decrease in proactive interference (PI) occurs, called PI release (Wickens, 1970). Therefore, if the above linguistic hypothesis is correct, a shift from the comparative degree to agentive nouns, or vice versa, should result in PI release.

In addition, the study also examined two theoretical issues: (1) Is PI and/or PI release a short-term or a longterm memory effect? And (2) is it due to an encoding or retrieval process? The method used to approach these problems involved the final free recall (FFR) paradigm and the cued recall procedure. Some support for the notion that PI and release from PI are secondary or long-term memory phenomena comes from the free recall literature (Craik \& Birtwistle, 1971) and from the PI release literature (Humphrey, Petrusic, \& Schwartz, 1972). Clearly, further research into the type of memory system involved in the PI release procedure is needed. This is one of the secondary goals of the present study.

Recently, Gardiner, Craik, and Birtwistle (1972) found evidence that seemed to support a retrieval explanation of PI and PI release. When shifting from a subset of a large category to another, they found PI release only when the appropriate subset name was given as a cue either during input or output on the critical shift trial. Since the subcategory cue was equally effective during the time of encoding or retrieval, a retrieval interpretation of the data was favored. The Gardiner et al. conclusions are equivocal. First, the study could also be used to support the notion that PI and release of PI are due to both a retrieval and an encoding process, with both factors contributing equally to recall. Second, the basis for the Gardiner et al. interpretation is that within-categories release can occur only with a cuing procedure. However, Wickens, Dalezman, and Eggemeier (1976) found subcategory 
release without any cuing procedure. The question now is, what can account for this inconsistency in the literature? It seems logical to point to task demands as the culprit. What Gardiner et al. called the control group was cued on the preshift and shift trials to process information only by the general category name. For the experimental group, the cue was changed on the shift trial. Thus, the Gardiner et al. findings could reflect nothing more than subjects' obeying the task demands-in one group, maintaining the general category strategy, and in the other, abandoning it. Gardiner et al. should have included a noncued shift and no-shift control to see whether subjects would normally use the subcategory dimensions. The Wickens et al. study indicates that the subcategory dimension is a viable feature that can normally be used by subjects. Using a completely different procedure, Watkins and Watkins (1975) suggested a cue overload (retrieval) interpretation of PI and PI release in the Brown-Peterson task. They found that FFR performance of initially untested categories was independent of within-categories list position on the original Brown-Peterson trials. This study also suffered from experimental design problems. The FFR results may (1) reflect nothing more than the effects of output interference, or (2) be a result of the experimental method used; that is, the untested category procedure is very similar if not identical to the intentional forgetting paradigm, where little if any interference is found for to-be-forgotten items (Bjork, 1972). If this is the case, it is not testing cue overload but intentional forgetting.

Further research into the nature of the release-fromPI phenomenon is needed. Using a totally different approach, the present study examined the retrieval and encoding hypotheses by providing the category dimension and initial letter of each word as cues during a second FFR test. The retrieval hypothesis would predict that cuing should reduce the differences between the shift and no-shift conditions.

\section{METHOD}

\section{Subjects}

The subjects were 96 introductory psychology students, fulfilling a course requirement.

\section{Materials}

Four lists of 12 words each were constructed with a mean Kucera and Francis (1967) frequency count of 18. Two of the lists consisted of 24 agentive nouns, while the other two lists of 24 words consisted of comparative adjectives. Within a list, the words were as semantically and acoustically unrelated as possible, with the only exception being their commonality of having an -er suffix.

\section{Procedure}

The materials were presented by a Carousel projector. A trial consisted of a 1.5-sec ready signal, followed by a word triad for $2.5 \mathrm{sec}$, a number subtraction task for $18 \mathrm{sec}$, and ending with an 8-sec recall signal.

For the control group, the word triads on all four trials were either comparative adjectives or agentive nouns. The experi- mental group, on the other hand, received the same comparative adjectives or agentive nouns for the first three trials, shifting to either agentive nouns or comparative adjectives, respectively, on the fourth trial. Each group consisted of 48 subjects, allowing for the counterbalancing of stimuli across trials and groups. The dependent variable was the number of words correctly recalled for each trial, with an additional point added on if all three words were recalled in the order of presentation.

The four trials were followed by a 5-min "phony debriefing" period. The subjects were then given a FFR test. A minimum recall period of $2 \mathrm{~min}$ was provided. Next, the subjects received a cued FFR test. The cues consisted of a narrative description of the appropriate -er categories, as well as the first letter of each word. Thus, the control subjects were told whether the words had been agentive nouns or comparative adjectives, while the experimental subjects were told that the words were from both of these categories. A full written explanation of the meaning of agentive nouns and comparative adjectives, including examples of words not previously shown from each category, was provided. In order to control for guessing effects, the initial letter of each word was also provided. For FFR, the dependent variable was the probability of correct FFR given prior correct recall.

\section{RESULTS}

The results of the PI release data as a function of trials and groups (experimental vs. control) are shown in Figure 1. On the first three trials, the only significant factor was a trial main effect $[F(2,176)=175.47$, $\mathrm{MSe}=.69]$. Thus, there were no group differences for the first three trials, but recall did decline over these trials, indicating a build-up of PI. On the critical fourth trial, the shift trial for the experimental group, only a significant group main effect was found $[\mathrm{F}(1,88)=47.36$, $\mathrm{MSe}=1.14]$, with the experimental group's recall performance exceeding that of the control group. The amount of recovery (using the method outlined by Wickens, 1970) for the experimental group was $56 \%$.

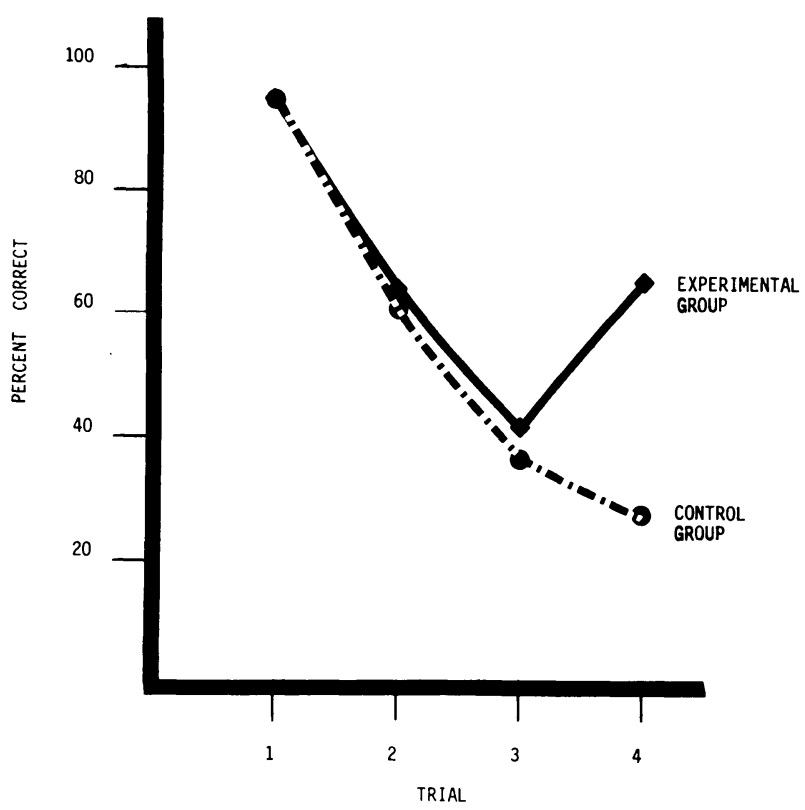

Figure 1. Percent recall as a function of trials and groups. 

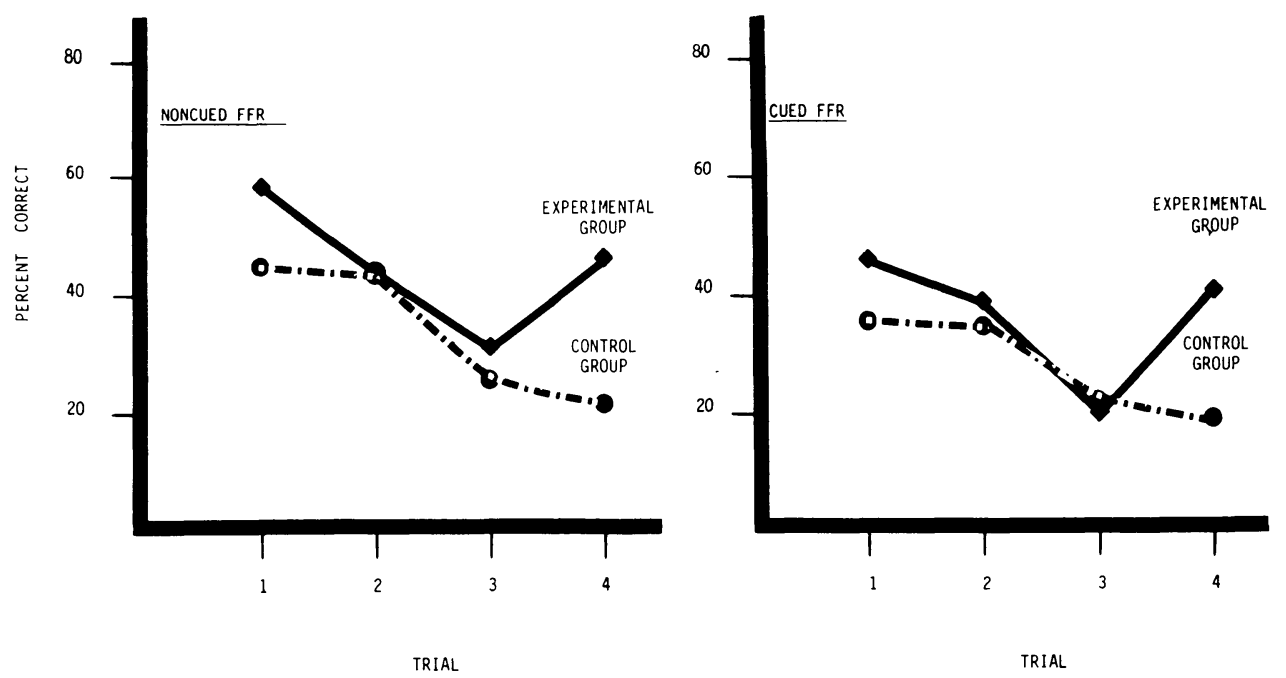

Figure 2. Conditional probability correct for items recalled during final free recall and as a function of trials, groups, and type of cuing procedure.

Both the noncued and cued FFR retention functions were conditionalized on the basis of correct initial recall and are shown in Figure 2. Trials in FFR are defined in terms of the original PI trials. An analysis of variance over the first three trials of FFR resulted only in a trial main effect [noncued FFR, $F(2,188)=15.40$, $\mathrm{MSe}=.28$; cued FFR, $\mathrm{F}(2,188)=12.71, \mathrm{MSe}=.26] . \mathrm{A}$ group main effect was found on Trial 4 [noncued FFR, $\mathrm{F}(1,94)=14.95, \mathrm{MSe}=.28 ;$ cued FFR, $\mathrm{F}(1,94)=16.88$, MSe $=.19]$. Clearly, the results replicated the initial PI release findings. The amount of recovery was .80 for noncued FFR and .82 for cued FFR, using the Wickens (1970) method. In addition, noncued FFR was superior to cued FFR $(.38$ vs. .32) $[F(1,94)=394.52$, $\mathrm{MSe}=.29]$.

A final analysis compared the extralist intrusion rate for noncued vs. cued recall. The number of intrusions was substantially higher for cued vs. noncued free recall (6.03 vs. 2.23$)[\mathrm{F}(1,95)=394.52, \mathrm{MSe}=1.73]$. The latter analysis will be discussed more fully in the Discussion section.

\section{DISCUSSION}

The results seem to support the linguistic hypothesis that the -er suffix is processed as one of two independent morphemes. Shifting from comparative adjectives to agentive nouns or vice versa resulted in significant PI release.

A possible confounding with the present design is that of syntactic class. One could argue that the above results might reflect changes in syntactic class rather than semantic meaning of the -er suffix. This hypothesis must presently be rejected, since Wickens (1970) found no evidence for PI release with shifts in grammatical class. In addition, an independent group of 24 subjects received the same lists of words, but without the -er suffix. Only a shift (experimental) group condition was run. Substantial PI was observed over all four trials, but no PI release. Although this is indicative of the absence of release from PI with a shift in grammatical class, it should be noted that this group is not really a completely adequate control. Without the -er suffix, subjects shift from verbs to adjectives or vice versa, while in the present experiment with the -er suffix, the shift is between nouns and adjectives.

As to whether the release effect is a short-term or long-term phenomenon, the final recall data clearly showed it is a longterm effect. The FFR performance paralleled the initial PI release findings. In fact, the amount of recovery was even greater for FFR than for the original PI release performance.

A comparison of cued vs. noncued FFR was to have ascertained whether the primary component of PI was inefficient retrieval. Surprisingly, cued final recall was inferior to noncued recall. A cursory inspection might lead to the conclusion that, at a minimum, the cuing effects indicated that retrieval was not the major factor in PI and release of PI. However, retrieval proponents could offer two arguments that would question the above conclusion: First, the decrease in cued recall could be due to forgetting over time; second, the effects of FFR cuing might have resulted in a response-generation strategy. That is, on the basis of the cues provided, the subject generated a potential pool of appropriate responses. Indirect support for the responsegeneration hypothesis comes from the extralist intrusion data: Greater intrusions were found with cued recall. It seems, then, that the cuing procedure used in this study is not an effective means of determining the source of PI and PI release. The potential confounding from response generation eliminated the possibility of testing the retrieval hypothesis. Other procedures must be developed to investigate this issue.

In conclusion, the present data indicated that the -er suffix can function as two independent morphemes: one a doer of action, and the other the comparative degree. The PI release procedure offers linguists what they have long searched for: an empirical means of establishing a morpheme dictionary. All that is needed is to shift from one class of morphemes to another and see whether there is release of PI.

\section{REFERENCES}

BJork, R. A. Theoretical implications of directed forgetting. In A. W. Melton \& E. Martin (Eds.), Coding process in human memory. Washington, D.C: Winston, 1972.

Сномsкy, N. Syntactic structures. The Hague, Netherlands: Norton, 1957. 
Сномsкy, N. Aspects of the theory of syntax. The Hague, Netherlands: Norton, 1965. (a)

CHOMsкY, N. Topics in the theory of generative grammar. The Hague, Netherlands: Norton, 1965. (b)

Craik. F. I. M., \& Birtwistle, J. Proactive inhibition in free recall. Journal of Experimental Psychology, 1971, 91, 120-123.

Gardiner, J. M., Craik, F. I. M., \& Birtwistle, J. Retrieval cues and release from proactive inhibition. Journal of Verbal Learning and Verbal Behavior, 1972, 11, 778-783.

Humphreys, N. S., Petrusic, W. M., \& Schwartz, R. M. Free recall following a switch in encoding class. Journal of Experimental Psychology, 1972, 95, 453-455.

JaRvella, R. J., \& SNodgrass, J. G. Seeing ring in rang and retain in retention: On recognizing stem morphemes in printed words. Journal of Verbal Learning and Verbal Behavior, 1974, 13. $590-598$.
KUČERA, H., \& FRANCIS, W. N. Computational analysis of presentday American English. Providence, R.I: Brown University Press, 1967.

Murrell, G. A., \& Morton, J. Word recognition and morpheme structure. Journal of Experimental Psychology, 1974, 102, 963-968.

Watkins, O. C., \& Watkins, M. J. Build-up of proactive interference as a one overload effect. Journal of Experimental Psychology: Human Learning and Memory, 1975, 104, 442-452.

WiCKENS, D. D. Encoding categories of words: An empirical approach to meaning. Psychological Review, 1970, 77, 1-15.

Wickens, D. D., Dalezman, R. E., \& Eggemeier, F. T. Multiple encoding of word attributes in memory. Memory \& Cognition, 1976, 4, 307-310.

(Received for publication September 27, 1978.) 